\title{
Triboelectric nanogenerator based on Teflon/vitamin B1 powder for self-powered humidity sensing
}

\author{
Liangyi Zhang ${ }^{1,2}$, Huan $\mathrm{Li}^{3}$, Yiyuan $\mathrm{Xie}^{* 1,2}$, Jing Guo ${ }^{* 1,2}$ and Zhiyuan Zhu ${ }^{1,2}$
}

\author{
Full Research Paper \\ Address: \\ ${ }^{1}$ Chongqing Key Laboratory of Nonlinear Circuits and Intelligent \\ Information Processing, College of Electronic and Information \\ Engineering, Southwest University, Chongqing, China, ${ }^{2}$ Key \\ Laboratory of Networks and Cloud Computing Security of Universities \\ in Chongqing, College of Electronic and Information Engineering, \\ Southwest University, Chongqing, China and ${ }^{3}$ Ocean College, \\ Zhejiang University, Zhejiang, China \\ Email: \\ Yiyuan Xie* - yyxie@swu.edu.cn; Jing Guo* - poem24@swu.edu.cn \\ * Corresponding author \\ Keywords: \\ humidity sensor; self-powered system; triboelectric nanogenerators \\ (TENGs); triboelectrification; vitamin B1
}

Beilstein J. Nanotechnol. 2020, 11, 1394-1401. https://doi.org/10.3762/bjnano.11.123

Received: 26 June 2020

Accepted: 18 August 2020

Published: 11 September 2020

This article is part of the thematic issue "Nanogenerators and flexible electronics".

Guest Editor: Y. Mao

(C) 2020 Zhang et al.; licensee Beilstein-Institut. License and terms: see end of document.

\begin{abstract}
Recently, there has been growing interest in triboelectric nanogenerators (TENGs) that can effectively convert various forms of mechanical energy input into electrical energy. In the present study, a novel Teflon/vitamin B1 powder based triboelectric nanogenerator (TVB-TENG) is proposed. Paper is utilized as a supporting platform for triboelectrification between a commercial Teflon tape and vitamin B1 powder. The measured open-circuit voltage was approximately $340 \mathrm{~V}$. The TVB-TENG can be applied as a humidity sensor and exhibits a linear and reversible response to the relative humidity of the environment. Moreover, the change in relative humidity is also indicated by the change in luminosity of a set of light-emitting diodes (LEDs) integrated in the TVBTENG system. The TVB-TENG proposed in this study illustrates a cost-effective method for portable power supply and sensing devices.
\end{abstract}

\section{Introduction}

Recently, there has been unprecedented advancement in the internet of things (IoT) technology, which includes environmental monitoring and intelligent community applications. Particularly, humidity sensing has been investigated in environmental monitoring, and in other sectors, such as agriculture, food safety, wearable electronics, and wireless sensor networks
[1-4]. However, conventional power generation is needed to supply energy to these sensor networks, which leads to increased energy usage and adverse impacts on the environment. More specifically, the degradation of the urban environment has been increasing due to the current life habits of the population [5-7]. Moreover, a variety of sensors are often placed in severe 
environmental conditions, which might restrict their power supply options [8-12]. As a result, several lines of research have been focused on the development of methods for harvesting energy from the surrounding environment and converting it into electrical power. Through the design of portable electronics and wireless sensor systems [13-16], which harvest energy from the environment, the adverse environmental effects caused by battery-powered systems can be mitigated [17-21]. Hence, the investigation of self-powered sensors which harvest energy from the surrounding environment is highly sustainable.

Triboelectric nanogenerators (TENGs) have been growing in popularity for use as a novel technology to harvest energy. TENGs have a significant impact on the advancement of wearable electronics, intelligent robots, and the IoT [22-28]. Presently, TENGs are used to harvest various forms of mechanical energy from the surrounding environment, such as acoustic energy, wind, vibrations and human motion [29-33]. Recently, TENG-based sensors have attracted increased attention [34-41]. In 2014, Ga-doped $\mathrm{ZnO}$ was used for the fabrication of piezohumidity sensors with a high sensitivity and a fast response [42]. In 2018, Vivekananthan et al. proposed sustainable energy harvesting and battery-free humidity sensors by using biocompatible collagen nanofibrils [43]. More recently, Zhang et al. developed a TENG-driven self-powered flexible humidity sensor based on a tin disulfide nanoflower/reduced graphene oxide $\left(\mathrm{SnS}_{2} / \mathrm{rGO}\right)$ hybrid nanomaterial [44]. However, the large-scale application of TENGs for humidity sensing is hindered by the high costs involved in their complex production and the high facility costs for particular manufacturing process. Thus, intensive research is required for the design of TENGs based on commercially available, cost-effective and feasible materials. Furthermore, TENGs should be seamlessly integrated and fabricated using a simple process, particularly regarding multifunctional sensing applications.

In the present study, a novel Teflon/vitamin B1 powder based triboelectric nanogenerator (TVB-TENG) is proposed. Vitamin B1 is an essential water-soluble vitamin which stays in the human body for only a few hours. Vitamin B1 is a coenzyme involved in the metabolism of sugar, protein and fat, which is found in grains, beans, pork, and other sources. Since it is costeffective, environmentally friendly, non-poisonous and soluble, vitamin B1 can be used as a lubricant to make a friction nanogenerator. Due to its sustainability and flexibility, paper can be used as a substrate and supporting structure. The conductive electrode is made of copper foil, while the triboelectric pair is comprised of Teflon tape and vitamin B1 powder. The approximate values of the output power density of the TVB-TENG can reach $120.13 \mu \mathrm{W} / \mathrm{cm}^{2}$. In addition, the approximate values of the open-circuit voltage $\left(V_{\mathrm{oc}}\right)$ and short-circuit current $\left(I_{\mathrm{sc}}\right)$ of this device were $340 \mathrm{~V}$ and $46.3 \mu \mathrm{A}$, respectively. These results indicate that sufficient power can be supplied to systems with low power requirements. As an extension of previous work [45], the self-powered TVB-TENG designed in this study can be used to measure the relative humidity and exhibits good linearity and reversibility. In addition, the materials used in the manufacturing of the TENGs are nontoxic and degradable. Furthermore, light-emitting diodes (LEDs) are integrated with the humidity sensor and the luminosity is an indicator of the relative humidity $(\mathrm{RH})$ from the surrounding environment.

\section{Experimental}

The conductive copper foil tape is used as the electrode, while the paper (manufacturer: Miao Ben) at the bottom serves as a supporting platform. The Teflon tape (manufacturer: RUIGUAN) is cut to the desired size $(4 \mathrm{~cm} \times 5 \mathrm{~cm})$ and pasted to the bottom of the conductive copper foil tape, serving as one element of the triboelectric pair. In addition, $\approx 20 \pm 5 \mathrm{mg}$ of vitamin B1 powder (manufacturer: Huazhong Pharmaceutical Co. LTD) is pressed against the bottom of another conductive copper foil tape with double-sided tape, working as the other element in the triboelectric pair. The fabrication process of the TVB-TENG proposed in this study is illustrated in Figure 1 and the actual price of the material used to make the TENG is only approximately CN¥ 0.5. An oscilloscope (probe: $100 \mathrm{M} \Omega$ ) was used to measure the voltage across the external load (a variable resistor) and a high-precision multifunctional electronic scale, with an accuracy of $0.001 \mathrm{~g}$, was used to measure the required amount of vitamin $\mathrm{B} 1$ powder.

\section{Results and Discussion}

As shown in Figure 2, the working mechanism of TVB-TENG is based on contact triboelectrification and electrostatic induction. First, when the device is externally compressed, electrons are transferred from the B1 vitamin membrane to the Teflon membrane. The contact surface between the vitamin B1 membrane and the Teflon membrane is separated in the absence of an external force. There is a positive charge transfer from the conductive copper foil tape at the bottom of the TVB-TENG, to the conductive copper foil tape at the top, leading to an electric field equilibrium due to electrostatic induction. As a result, a potential difference between the electrodes is generated. Subsequently, when the TVB-TENG is pressed again, an opposite potential difference is produced due to the triboelectrification principle. As such, there is a positive charge transfer from the top of the conductive copper foil tape of the TVB-TENG to the bottom one [46]. Therefore, it is expected that TVB-TENGs can produce a stable output power under the sustained effect of an external force. The potential distribution is illustrated to obtain a comprehensive understanding of this phenomenon. 


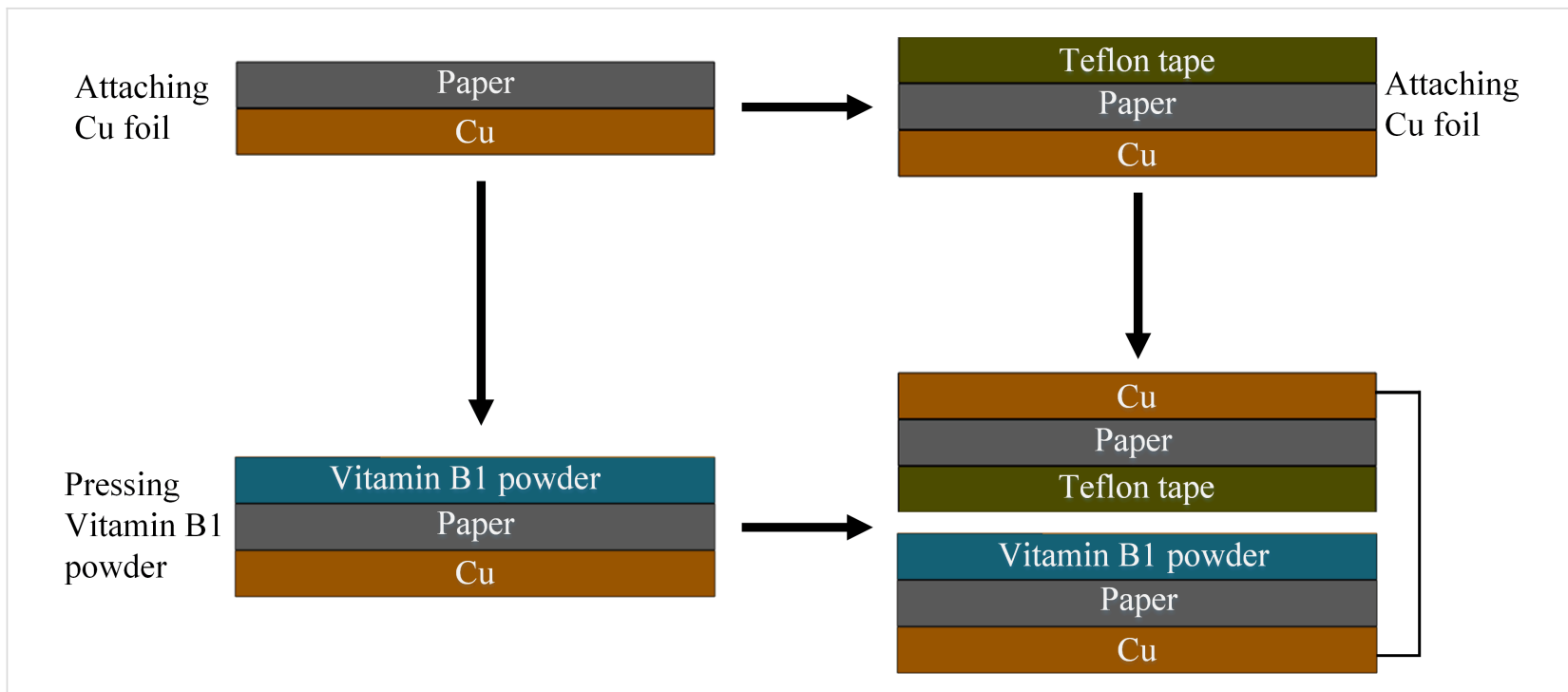

Figure 1: The manufacturing process of the TVB-TENG structure.
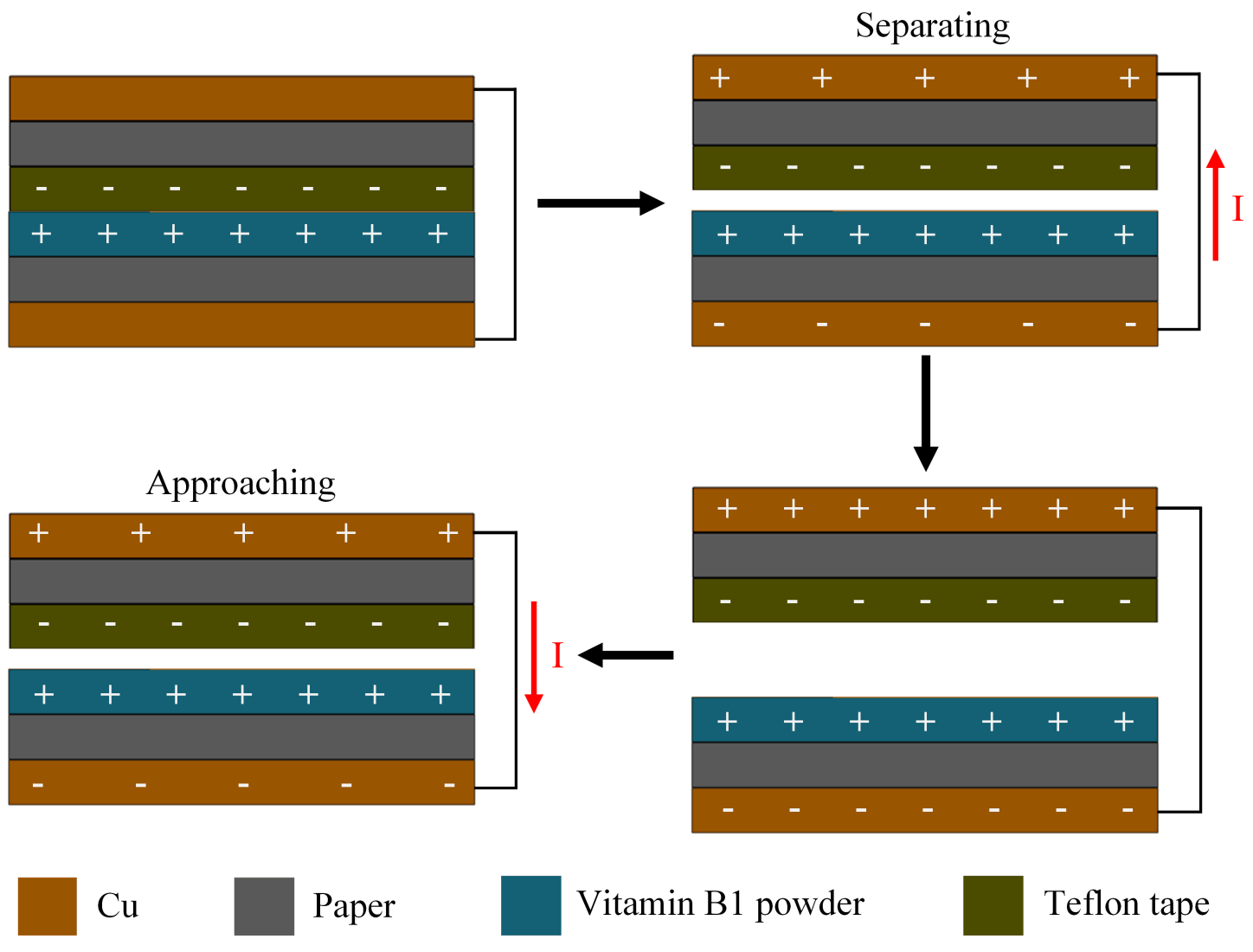

Teflon tape

Figure 2: The working mechanism of the TVB-TENG structure.

An oscilloscope (probe: $100 \mathrm{M} \Omega$ ) was used to measure the voltage across the external load (a variable resistor). The output current was calculated by using the measured voltage and the load resistance. As illustrated in Figure $3 \mathrm{a}$ and Figure 3b, the output voltage and the current reached a peak at $340 \mathrm{~V}$ and $46.3 \mu \mathrm{A}$, corresponding to a load resistance of $100 \mathrm{M} \Omega$ and $100 \mathrm{k} \Omega$, respectively. As shown in Figure 3c, when the load resistance was increased from $100 \mathrm{k} \Omega$ to $100 \mathrm{M} \Omega$, the measured 
(a)

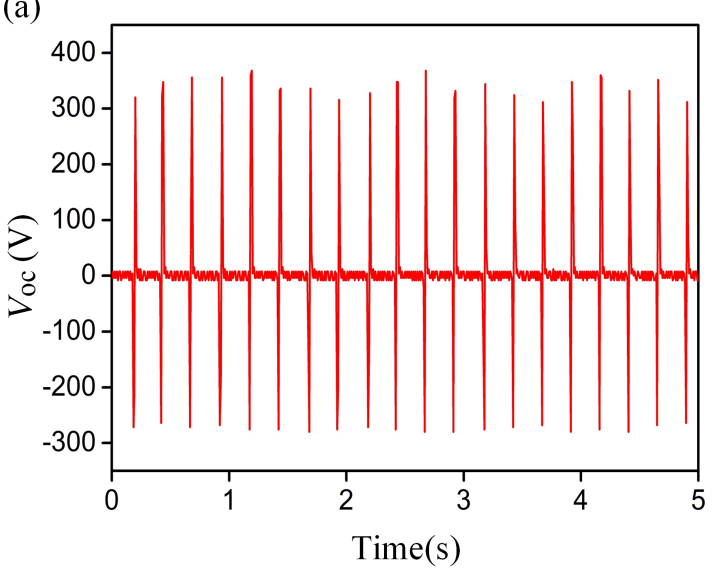

(c)

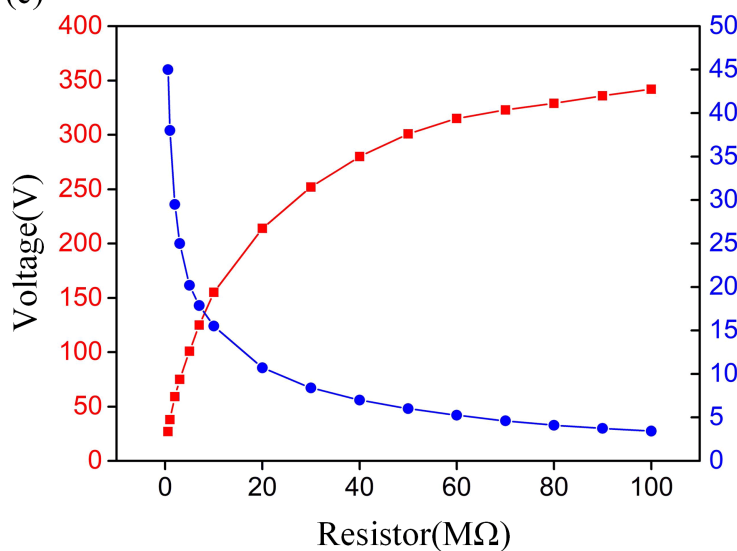

(e)

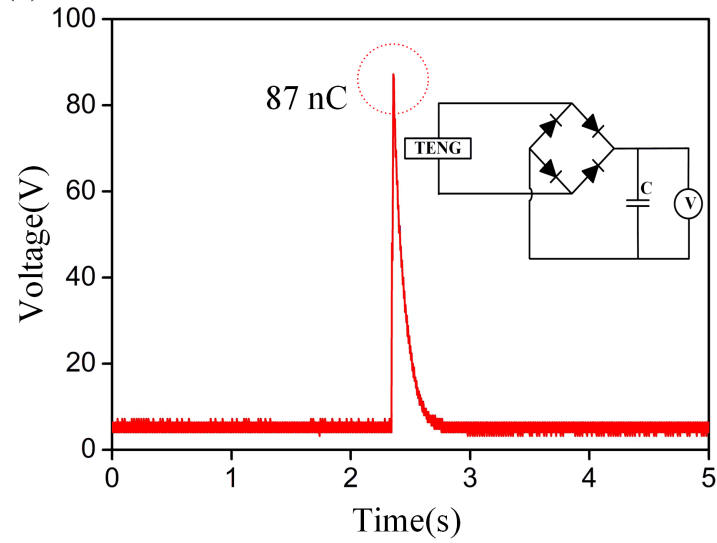

(b)

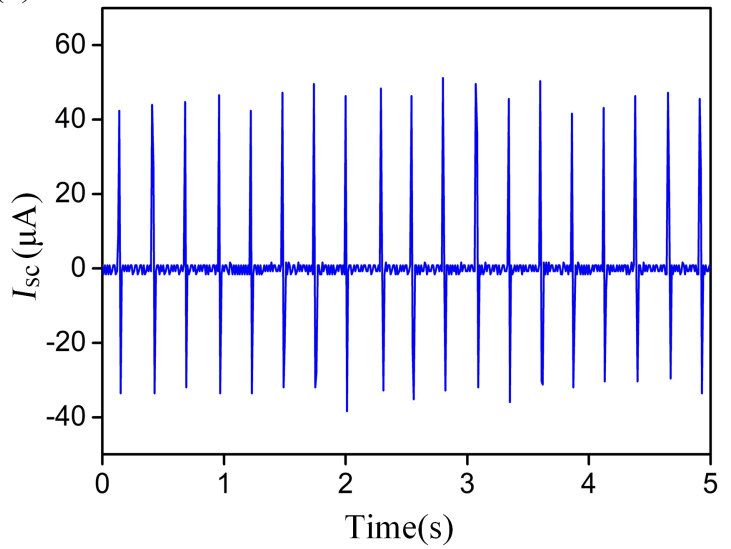

(d)

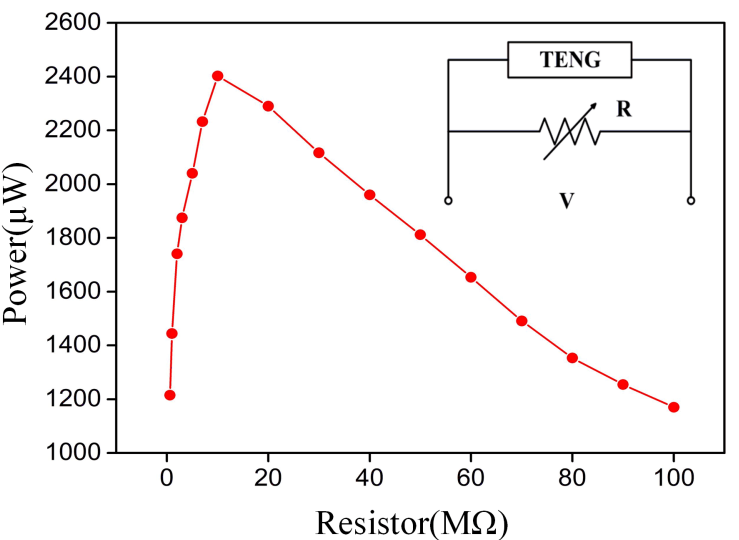

(f)

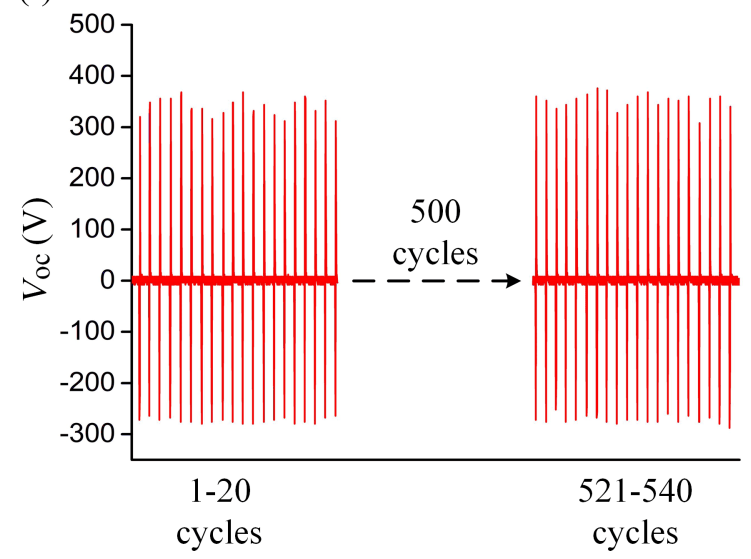

Figure 3: (a) The output voltage (matched load of $100 \mathrm{M} \Omega$ ) and (b) short-circuit current (matched load of $100 \mathrm{k} \Omega$ ) in a TENG. (c) The behavior of the output voltage and short-circuit current upon changing the load resistance. (d) The behavior of the output power density upon changing the load resistance. (e) TVB-TENG with a full-wave bridge rectifier for charging a $1 \mathrm{nF}$ capacitor. In one cycle, $87 \mathrm{nC}$ of charge is transferred. (f) The reliability of TVB-TENG was studied over 500 working cycles.

output voltage showed an increasing trend. As shown in Figure $3 \mathrm{~d}$, the output power reached its peak at $2402.5 \mu \mathrm{W}$ at a loading resistance of $10 \mathrm{M} \Omega$. Accordingly, the fabricated internal resistance of the TENGs was close to $10 \mathrm{M} \Omega$. Consequently, considering the size of the fabricated TENG $(4 \mathrm{~cm} \times 5 \mathrm{~cm})$, the maximum power density is $120.13 \mu \mathrm{W} / \mathrm{cm}^{2}$.
Since an external resistance of $100 \mathrm{M} \Omega$ is much higher than $10 \mathrm{M} \Omega$ (roughly equal to the internal resistance), the output voltage (at a $100 \mathrm{M} \Omega$ load) is approximated to be equal to the open circuit voltage. Similarly, for a load of $100 \mathrm{k} \Omega$, the corresponding output current can be considered to be equal to the short circuit current. In addition, as shown in Figure 3e, the 
charging capacity of the prepared TVB-TENG was investigated by integrating a full-wave rectifier bridge to charge a $1 \mathrm{nF}$ capacitor. The maximum capacitive voltage was $87 \mathrm{~V}$, and in one cycle, a charge of $87 \mathrm{nC}$ was transferred. The reliability of the manufactured TVB-TENG was also investigated. As shown in Figure 3f, the output voltage of the TENG remains steady even after 500 external force testing cycles.

The TENG output is affected by the humidity due to the triboelectric effect, and the preservation of the triboelectric charge at the surface is severely decreased by the humid environment [47]. It should be considered that the experiments with the
TVB-TENG were performed in Chongqing, located in the southern region of China where it rains often and the annual relative humidity is usually above $40 \%$. Thus, the humidity sensor response is limited due to a change in $\mathrm{RH}$ from 40 to 90\% (Figure $4 \mathrm{a}-\mathrm{f}$ ). The dynamic change between the output voltage and the $\mathrm{RH}$ can be derived from the $2 \mathrm{D}$ graph. As the $\mathrm{RH}$ increased, there was a declining trend in the output signal. Figure 4 shows the output voltage of the TVB-TENG upon a change in RH. The output voltages of $371 \mathrm{~V}, 331 \mathrm{~V}, 247 \mathrm{~V}$, $180 \mathrm{~V}, 137 \mathrm{~V}$ and $105 \mathrm{~V}$ corresponded to RH levels of $40 \%$, $50 \%, 60 \%, 70 \%, 80 \%$ and $90 \%$, respectively. As illustrated in Figure $5 \mathrm{a}$, the output voltage as a function of $\mathrm{RH}$ has a linear
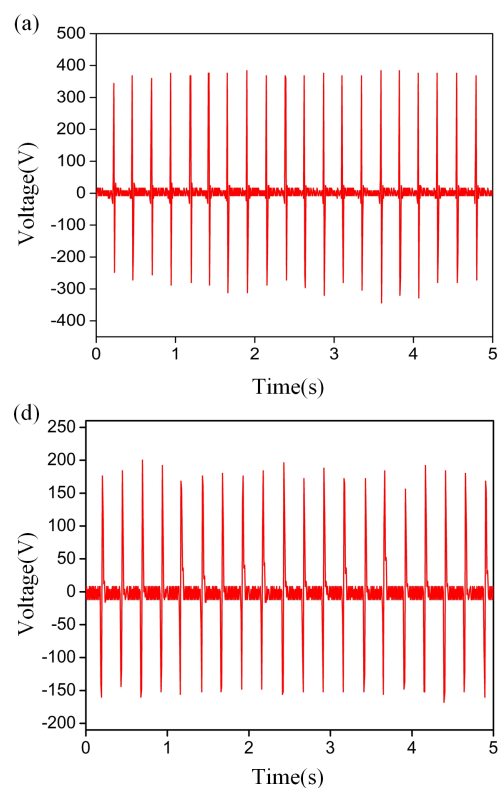
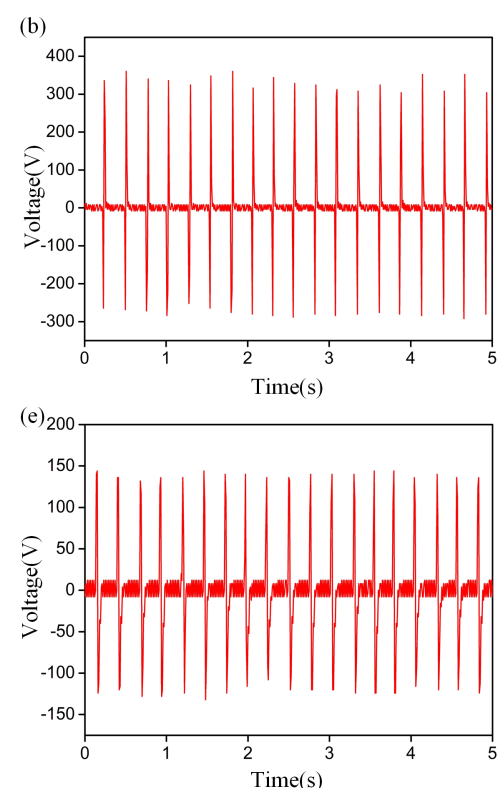

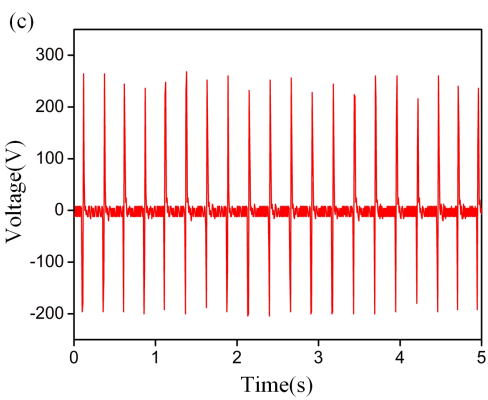

(f)

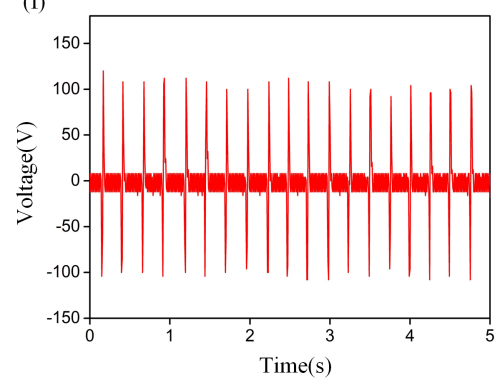

Figure 4: The output voltage sensor feedback at different humidity levels: $40 \%$ (a), $50 \%$ (b), $60 \%$ (c), $70 \%$ (d), $80 \%$ (e) and $90 \%$ (f).
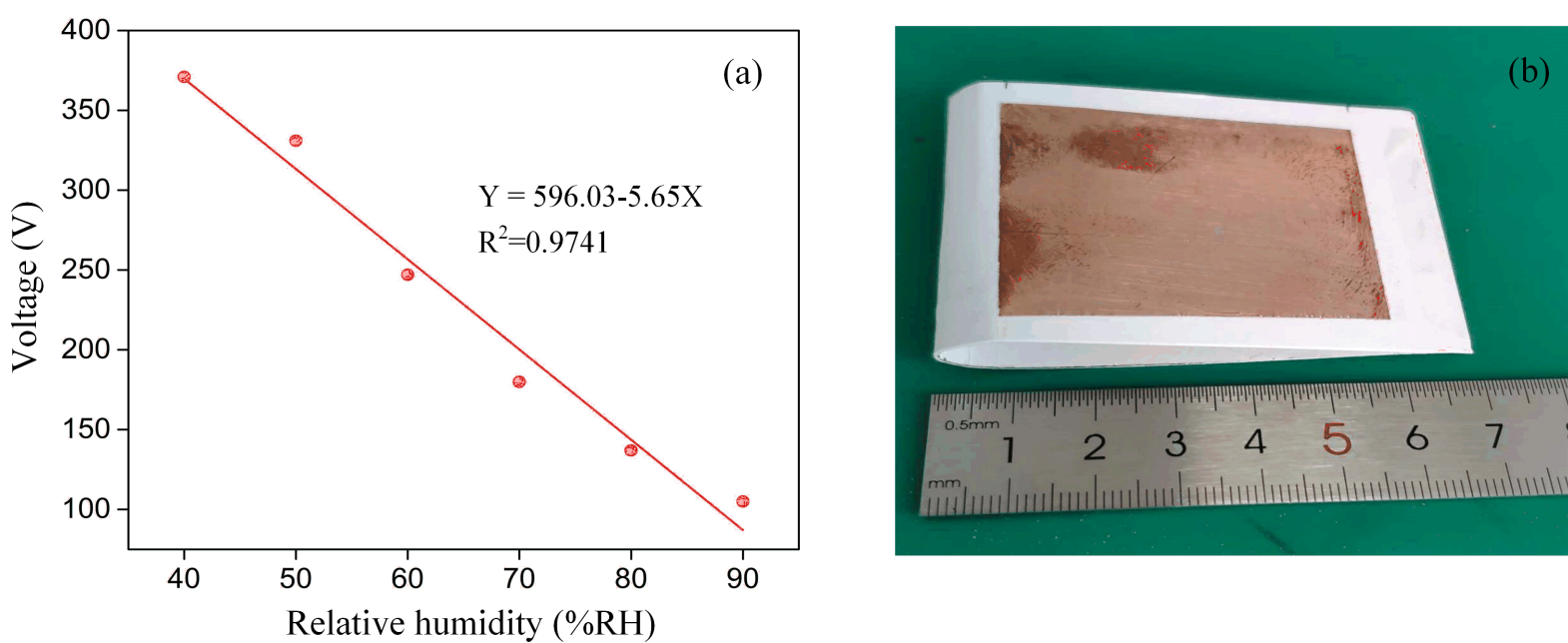

Figure 5: (a) The output voltage of the TVB-TENG as a function of RH (40-90\%). (b) A representative photograph of the TVB-TENG. 
fitting and the fitting equation for the output voltage $(Y)$ and the relative humidity $(X)$ can be represented as $Y=596.03-5.65 X$, with an $R$-squared value of 0.9741 . A representative photograph of the TVB-TENG is shown in Figure 5b. Table 1 presents the humidity-sensing characteristics of the proposed humidity sensor in comparison with previously published studies $[42-44,48,49]$. The response and measurement range of the manufactured sensor are comparable to the sensor made from collagen-cotton fabric via the freeze-dried method [43].
Furthermore, the reversibility of the TVB-TENG in terms of humidity sensing characteristics was also studied, as shown in Figure 6a. Thirty blue LEDs (according to the product specification of these $3 \mathrm{~mm}$ LEDs the voltage range is $1.8-2.2 \mathrm{~V}$ ) were connected to the TENG humidity sensor as a real-time indicator of changes in the RH. The tests were conducted in environments with different RHs, and the luminosity of the LEDs was an indicator of changes in the RH. As illustrated in Figure $6 \mathrm{~b}$, when the surrounding humidity changes drastically, the change in the LED system luminosity can act as an alarm.

\begin{tabular}{|c|c|c|c|c|c|}
\hline Sensor type & Sensing material & Fabrication method & Measurement range & Response & Ref. \\
\hline voltage-type & Ga-doped ZnO & hydrothermal method & $45-80 \% \mathrm{RH}$ & 358 & [42] \\
\hline current-type & collagen-cotton fabric & freeze-dried method & $50-90 \% \mathrm{RH}$ & $0.1287 \mu \mathrm{A} / \% \mathrm{RH}$ & [43] \\
\hline voltage-type & $\mathrm{SnS}_{2} / \mathrm{rGO}$ & screen-printing method & $0-97 \% \mathrm{RH}$ & 65 & {$[44]$} \\
\hline voltage-type & Al-doped $\mathrm{ZnO}$ & $\begin{array}{l}\text { seed-assisted wet-chemical } \\
\text { method }\end{array}$ & $15-60 \% \mathrm{RH}$ & 1522 & {$[48]$} \\
\hline voltage-type & Fe-doped ZnO & $\begin{array}{l}\text { seed-assisted wet-chemical } \\
\text { method }\end{array}$ & $5-65 \% \mathrm{RH}$ & 305 & {$[49]$} \\
\hline voltage-type & vitamin B powder & powder machine method & $40-90 \% \mathrm{RH}$ & $5.65 \mathrm{~V} / \% \mathrm{RH}$ & current work \\
\hline
\end{tabular}

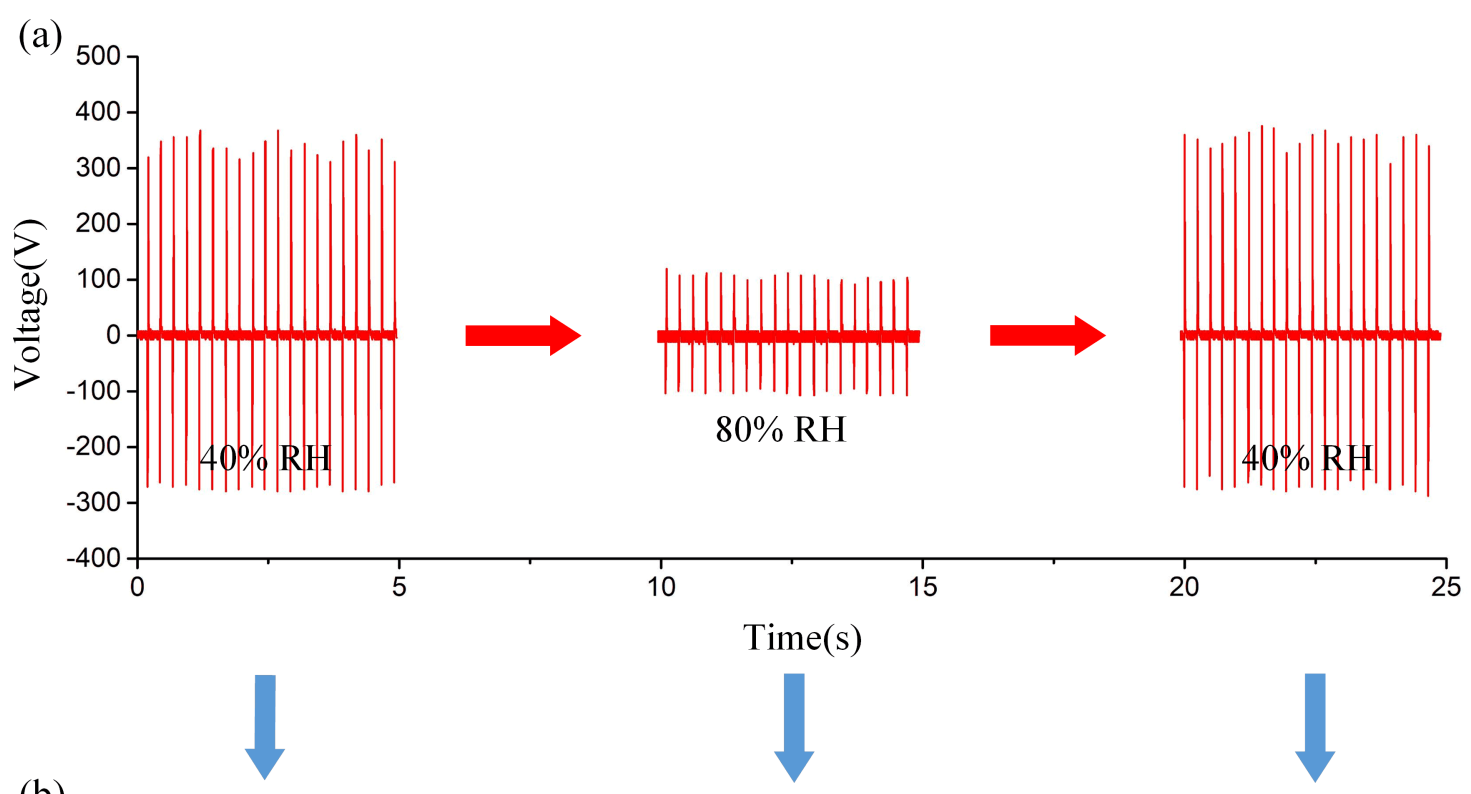

(b)
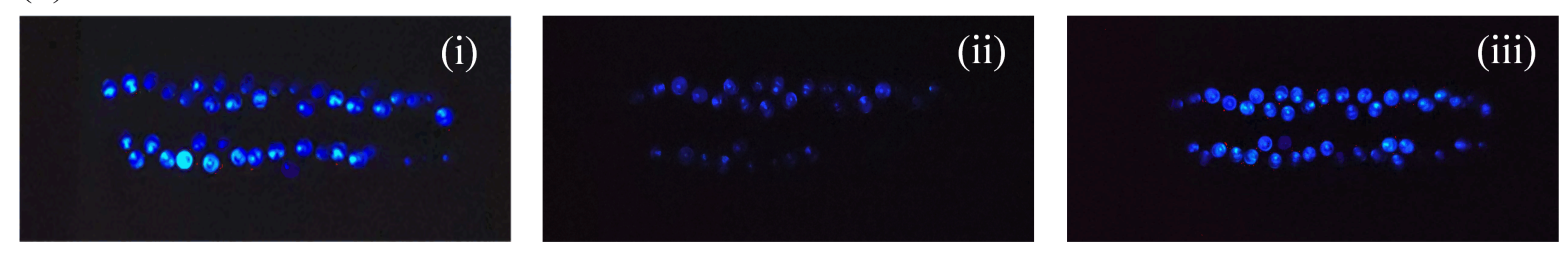

Figure 6: (a) Reversibility of a TVB-TENG-based humidity sensor. (b) The change in luminosity of thirty LEDs under different relative humidity conditions. 


\section{Conclusion}

This study proposed a novel TVB-TENG using vitamin B1 powder and Teflon tape. The fabricated device integrates a selfpowered energy supply with a sensing system, and the change in relative humidity of the surrounding environment is properly detected. According to the experimental analysis, the results show that the TVB-TENG has a distinct humidity response. Further, the change in RH was also illustrated via the luminosity changes of the integrated LEDs. The device proposed in this study has great application potential in the area of environmental monitoring.

\section{Funding}

This research was supported by Zhejiang Provincial Natural Science Foundation of China (Grant No. LY20F040004), the Fundamental Research Funds for the Central Universities (Grant No. SWU019040), National Natural Science Foundation of China (Grant No. 61804132) and Zhoushan Municipal Government.

\section{References}

1. Wang, J.; Zhang, H.; Xie, Y.; Yan, Z.; Yuan, Y.; Huang, L.; Cui, X.; Gao, M.; Su, Y.; Yang, W.; Lin, Y. Nano Energy 2017, 33, 418-426. doi:10.1016/j.nanoen.2017.01.055

2. Jiang, J.; Wang, Q.; Wang, B.; Dong, J.; Li, Z.; Li, X.; Zi, Y.; Li, S.; Wang, X. Nano Energy 2019, 59, 545-552. doi:10.1016/j.nanoen.2019.02.066

3. Wang, X.; Dai, Y.; Liu, R.; He, X.; Li, S.; Wang, Z. L. ACS Nano 2017, 11, 8339-8345. doi:10.1021/acsnano.7b03560

4. Tang, W.; Jiang, T.; Fan, F. R.; Yu, A. F.; Zhang, C.; Cao, X.; Wang, Z. L. Adv. Funct. Mater. 2015, 25, 3718-3725. doi:10.1002/adfm.201501331

5. Luo, J.; Xu, L.; Tang, W.; Jiang, T.; Fan, F. R.; Pang, Y.; Chen, L.; Zhang, Y.; Wang, Z. L. Adv. Energy Mater. 2018, 8, 1800889. doi:10.1002/aenm.201800889

6. Liu, D.; Bao, J.-F.; Chen, Y.-L.; Li, G.-K.; Zhang, X.-S. Nano Energy 2020, 74, 104770. doi:10.1016/j.nanoen.2020.104770

7. Ding, W.; Zhou, J.; Cheng, J.; Wang, Z.; Guo, H.; Wu, C.; Xu, S.; Wu, Z.; Xie, X.; Wang, Z. L. Adv. Energy Mater. 2019, 9, 1901320. doi:10.1002/aenm.201901320

8. Zhang, N.; Qin, C.; Feng, T.; Li, J.; Yang, Z.; Sun, X.; Liang, E.; Mao, Y.; Wang, X. Nano Res. 2020, 13, 1903-1907. doi:10.1007/s12274-020-2654-7

9. Lai, S.-N.; Chang, C.-K.; Yang, C.-S.; Su, C.-W.; Leu, C.-M.; Chu, Y.-H.; Sha, P.-W.; Wu, J. M. Nano Energy 2019, 60, 715-723. doi:10.1016/j.nanoen.2019.03.067

10. Li, X.; Lin, Z.-H.; Cheng, G.; Wen, X.; Liu, Y.; Niu, S.; Wang, Z. L. ACS Nano 2014, 8, 10674-10681. doi:10.1021/nn504243j

11. Yu, Y.; Wang, Y.; Zhang, S.; Zhang, P.; Xue, S.; Xie, Y.; Zhou, Z.; Li, J.; Kang, J. Nano Energy 2019, 61, 604-610. doi:10.1016/j.nanoen.2019.05.014

12. Mao, Y.; Geng, D.; Liang, E.; Wang, X. Nano Energy 2015, 15 , 227-234. doi:10.1016/j.nanoen.2015.04.026

13. Ning, C.; Tian, L.; Zhao, X.; Xiang, S.; Tang, Y.; Liang, E.; Mao, Y. J. Mater. Chem. A 2018, 6, 19143-19150. doi:10.1039/c8ta07784c
14. Xie, L.; Chen, X.; Wen, Z.; Yang, Y.; Shi, J.; Chen, C.; Peng, M.; Liu, Y.; Sun, X. Nano-Micro Lett. 2019, 11, 39. doi:10.1007/s40820-019-0271-3

15. Su, Y.; Wang, J.; Wang, B.; Yang, T.; Yang, B.; Xie, G.; Zhou, Y.; Zhang, S.; Tai, H.; Cai, Z.; Chen, G.; Jiang, Y.; Chen, L.-Q.; Chen, J. ACS Nano 2020, 14, 6067-6075. doi:10.1021/acsnano.0c01804

16. Wang, S.; Jiang, Y.; Tai, H.; Liu, B.; Duan, Z.; Yuan, Z.; Pan, H.; Xie, G.; Du, X.; Su, Y. Nano Energy 2019, 63, 103829. doi:10.1016/j.nanoen.2019.06.025

17. Tang, Y.; Zhou, H.; Sun, X.; Diao, N.; Wang, J.; Zhang, B.; Qin, C.; Liang, E.; Mao, Y. Adv. Funct. Mater. 2020, 30, 1907893. doi:10.1002/adfm.201907893

18. He, Q.; Wu, Y.; Feng, Z.; Sun, C.; Fan, W.; Zhou, Z.; Meng, K.; Fan, E.; Yang, J. Nano Energy 2019, 59, 689-696. doi:10.1016/j.nanoen.2019.03.005

19. Zhang, B.; Tang, Y.; Dai, R.; Wang, H.; Sun, X.; Qin, C.; Pan, Z.; Liang, E.; Mao, Y. Nano Energy 2019, 64, 103953. doi:10.1016/j.nanoen.2019.103953

20. Wu, C.; Tetik, H.; Cheng, J.; Ding, W.; Guo, H.; Tao, X.; Zhou, N.; Zi, Y.; Wu, Z.; Wu, H.; Lin, D.; Wang, Z. L. Adv. Funct. Mater. 2019, 29, 1901102. doi:10.1002/adfm.201901102

21. Zhou, Z.; Li, X.; Wu, Y.; Zhang, H.; Lin, Z.; Meng, K.; Lin, Z.; He, Q.; Sun, C.; Yang, J.; Wang, Z. L. Nano Energy 2018, 53, 501-507. doi:10.1016/j.nanoen.2018.08.055

22. Mao, Y.; Zhang, N.; Tang, Y.; Wang, M.; Chao, M.; Liang, E. Nanoscale 2017, 9, 14499-14505. doi:10.1039/c7nr05222g

23. Zhang, Y.; Wu, M.; Zhu, Q.; Wang, F.; Su, H.; Li, H.; Diao, C.; Zheng, H.; Wu, Y.; Wang, Z. L. Adv. Funct. Mater. 2019, 29, 1904259. doi:10.1002/adfm.201904259

24. Li, Z.; Zhu, M.; Shen, J.; Qiu, Q.; Yu, J.; Ding, B. Adv. Funct. Mater. 2020, 30, 1908411. doi:10.1002/adfm.201908411

25. Cui, X.; Zhang, H.; Cao, S.; Yuan, Z.; Ding, J.; Sang, S. Nano Energy 2018, 52, 71-77. doi:10.1016/j.nanoen.2018.07.037

26. Jiang, C.; Li, X.; Ying, Y.; Ping, J. Nano Energy 2020, 74, 104863. doi:10.1016/j.nanoen.2020.104863

27. Zhang, Y.; Peng, M.; Liu, Y.; Zhang, T.; Zhu, Q.; Lei, H.; Liu, S.; Tao, Y.; Li, L.; Wen, Z.; Sun, X. ACS Appl. Mater. Interfaces 2020, 12 , 19384-19392. doi:10.1021/acsami.9b22572

28. Ding, W.; Wang, A. C.; Wu, C.; Guo, H.; Wang, Z. L. Adv. Mater. Technol. (Weinheim, Ger.) 2019, 4, 1800487. doi:10.1002/admt.201800487

29. Luo, J.; Wang, Z.; Xu, L.; Wang, A. C.; Han, K.; Jiang, T.; Lai, Q.; Bai, Y.; Tang, W.; Fan, F. R.; Wang, Z. L. Nat. Commun. 2019, 10, 5147. doi:10.1038/s41467-019-13166-6

30. Wang, M.; Zhang, J.; Tang, Y.; Li, J.; Zhang, B.; Liang, E.; Mao, Y.; Wang, X. ACS Nano 2018, 12, 6156-6162. doi:10.1021/acsnano.8b02562

31. Chen, F.; Wu, Y.; Ding, Z.; Xia, X.; Li, S.; Zheng, H.; Diao, C.; Yue, G.; Zi, Y. Nano Energy 2019, 56, 241-251. doi:10.1016/j.nanoen.2018.11.041

32. Lin, H.; He, M.; Jing, Q.; Yang, W.; Wang, S.; Liu, Y.; Zhang, Y.; Li, J.; Li, N.; Ma, Y.; Wang, L.; Xie, Y. Nano Energy 2019, 56, 269-276. doi:10.1016/j.nanoen.2018.11.037

33. Wang, M.; Zhang, N.; Tang, Y.; Zhang, H.; Ning, C.; Tian, L.; Li, W.; Zhang, J.; Mao, Y.; Liang, E. J. Mater. Chem. A 2017, 5, 12252-12257. doi:10.1039/c7ta02680c

34. Xie, X.; Zhang, Y.; Chen, C.; Chen, X.; Yao, T.; Peng, M.; Chen, X.; Nie, B.; Wen, Z.; Sun, X. Nano Energy 2019, 65, 103984. doi:10.1016/j.nanoen.2019.103984 
35. Cheng, P.; Sun, M.; Zhang, C.; Guo, H.; Shi, J.; Zhang, Y.; Liu, Y.; Wang, J.; Wen, Z.; Sun, X. IEEE Trans. Nanotechnol. 2020, 19, 230-235. doi:10.1109/tnano.2020.2976154

36. Chen, C.; Wen, Z.; Wei, A.; Xie, X.; Zhai, N.; Wei, X.; Peng, M.; Liu, Y.; Sun, X.; Yeow, J. T. W. Nano Energy 2019, 62, 442-448. doi:10.1016/j.nanoen.2019.05.029

37. Lin, H.; Liu, Y.; Chen, S.; Xu, Q.; Wang, S.; Hu, T.; Pan, P.; Wang, Y.; Zhang, Y.; Li, N.; Li, Y.; Ma, Y.; Xie, Y.; Wang, L. Nano Energy 2019, 65, 103944. doi:10.1016/j.nanoen.2019.103944

38. Su, Y.; Yao, M.; Xie, G.; Pan, H.; Yuan, H.; Yang, M.; Tai, H.; Du, X.; Jiang, Y. Appl. Phys. Lett. 2019, 115, 073504. doi:10.1063/1.5110334

39. Su, Y.; Xie, G.; Tai, H.; Li, S.; Yang, B.; Wang, S.; Zhang, Q.; Du, H.; Zhang, H.; Du, X.; Jiang, Y. Nano Energy 2018, 47, 316-324. doi:10.1016/j.nanoen.2018.02.031

40. Su, Y.; Xie, G.; Wang, S.; Tai, H.; Zhang, Q.; Du, H.; Zhang, H.; Du, X.; Jiang, Y. Sens. Actuators, B 2017, 251, 144-152. doi:10.1016/j.snb.2017.04.039

41. Su, Y.; Yang, T.; Zhao, X.; Cai, Z.; Chen, G.; Yao, M.; Chen, K.; Bick, M.; Wang, J.; Li, S.; Xie, G.; Tai, H.; Du, X.; Jiang, Y.; Chen, J. Nano Energy 2020, 74, 104941. doi:10.1016/j.nanoen.2020.104941

42. Zhao, T.; Fu, Y.; Zhao, Y.; Xing, L.; Xue, X. J. Alloys Compd. 2015, 648, 571-576. doi:10.1016/j.jallcom.2015.07.035

43. Vivekananthan, V.; Alluri, N. R.; Purusothaman, Y.; Chandrasekhar, A.; Selvarajan, S.; Kim, S.-J. ACS Appl. Mater. Interfaces 2018, 10, 18650-18656. doi:10.1021/acsami.8b02915

44. Zhang, D.; Xu, Z.; Yang, Z.; Song, X. Nano Energy 2020, 67, 104251. doi:10.1016/j.nanoen.2019.104251

45. Xia, K.; Zhu, Z.; Zhang, H.; Du, C.; Wang, R.; Xu, Z. Microelectron. Eng. 2018, 199, 114-117. doi:10.1016/j.mee.2018.08.002

46. Han, Y.; Han, Y.; Zhang, X.; Li, L.; Zhang, C.; Liu, J.; Lu, G.; Yu, H.-D.; Huang, W. ACS Appl. Mater. Interfaces 2020, 12, 16442-16450. doi:10.1021/acsami.0c01061

47. Nguyen, V.; Zhu, R.; Yang, R. Nano Energy 2015, 14, 49-61. doi:10.1016/j.nanoen.2014.11.049

48. Zang, W.; Wang, W.; Zhu, D.; Xing, L.; Xue, X. RSC Adv. 2014, 4, 56211-56215. doi:10.1039/c4ra10216a

49. Zhu, D.; Hu, T.; Zhao, Y.; Zang, W.; Xing, L.; Xue, X. Sens. Actuators, B 2015, 213, 382-389. doi:10.1016/j.snb.2015.02.119

\section{License and Terms}

This is an Open Access article under the terms of the Creative Commons Attribution License (https://creativecommons.org/licenses/by/4.0). Please note that the reuse, redistribution and reproduction in particular requires that the authors and source are credited.

The license is subject to the Beilstein Journal of Nanotechnology terms and conditions: (https://www.beilstein-journals.org/bjnano)

The definitive version of this article is the electronic one which can be found at: https://doi.org/10.3762/bjnano.11.123 